\title{
ENVIRONMENTAL DEGRADATION AND ITS EFFECTS IN MORADABAD DISTRICT
}

\section{मुरादाबाद जनपद में पर्यावरणीय निम्नीकरण और उसके प्रभाव}

\author{
Dr. S.K. Sharma ${ }^{1}$, Brahm Singh 2 \\ ${ }^{1}$ Research Director, Associate Professor, Hindu College, Geography Department, Moradabad, India \\ 2 Researcher MA, NET, JRF, Department of Geography Hindu College, Moradabad, India
}

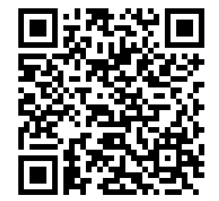

DOI: https://doi.org/10.29121/granthaalayah.v8.i10.2020.1957

Article Type: Research Article

Article Citation: Dr. S.K. Sharma, and Brahm Singh. (2020).

ENVIRONMENTAL DEGRADATION

AND ITS EFFECTS IN MORADABAD

DISTRICT. International Journal of

Research -GRANTHAALAYAH,

8(10), 176-181.

https://doi.org/10.29121/granthaa

layah.v8.i10.2020.1957

Received Date: 08 October 2020

Accepted Date: 30 October 2020

Keywords:

मुरादाबाद

पर्यावरणीय

प्रभाव

\section{ABSTRACT}

English: The research study area presented in Moradabad district is a study of environmental degradation and its effect that every person continuously tries to improve his future. Perhaps it is right at the level of personal development, but the current activities of human beings at the level of the environment, only point towards its sensitivity. The current growing problems of the environment around us such as the loss of the actual properties of the soil, unwanted changes in the air composition, rapid rise in the level of water pollutants, rapid loss of biodiversity, rapid rise of noise pollution, incurable and health diseases. Adi is like future crisis on human existence along with environment. At the core of these problems, some natural morals and values are being left behind day by day. The basic forms of nature resources such as water resources, air resources, soil resources, vegetation resources, fauna etc. are changing due to which the nature of problems like soil continuity, global warming and increase in climate and nature disasters, drinking water problem etc. Has taken the researcher has shown the effects of urbanization of Moradabad district in its study area on the environment and the present problems of environmental degradation and its effects. The effects of the study have been evaluated on the short-term and long-term effects of the effects on various components of the environment.

Hindi: प्रस्तुत शोध अध्ययन क्षेत्र मुरादाबाद जनपद में पर्यावरण निम्नीकरण और उसके प्र्रभाव का अध्ययन है कि प्रत्येक मनुष्य अपने भविष्य को बेहतर बनाने का निरंतर प्रयास करता है। शायद व्यक्तिगत विकास के स्तर पर तो यह सही है, परन्तु पर्यावरण केस्तर पर मनुष्य की वर्तमान गतिविधियाँ, उसकी संवेदनशीलता की ओर ही इशारा करती है। हमारे आस-पास के वातावरण की वर्तमान बढ़ती समस्याऐं जैसे मृदा के वास्तविक गुणों का ह्नास, वायु असंगठन में अवांछित परिवर्तन, जल प्रदूषकों के स्तर का तेजी से वृद्धि, जैवविविधता का तेजी से ह्नास, ध्वनि प्रदूषण, असाध्य व स्वास्थ्य रोगों का तेजी से वृद्धि आदि पर्यावरण के साथ-साथ मानव अस्तित्व पर भविष्य संकट की तरह है। इन समस्याओं के मूल में कुछ प्राकृतिक नैतिकता एवु मूल्यों को दिन-प्रतिदिन पीछे छोड़ते जा रहे हैं। प्रकृति संसाधनों में जैसे जल संसाधन, वायु संसाधन, मृदा संसाधन, वनस्पति संसाधन, जीव-जन्तुओं आदि के मूल स्वरूप बदलते जा रहे हैं जिससे मृदा अनुर्वतता, वैश्विक तायन एवं जलवायु एवं प्रकृति आपदाओं में वृद्धि, पेय जल की समस्या आदि जैसी समस्याओं का रूप धारण कर लिया है। शोधार्थी ने अपने अध्ययन क्षेत्र जनपद मुरादाबाद के नगरीकरण का वातावरण पर पड़ने वाले प्रभावों को पर्यावरण के निम्नीकरण एवं उसके प्रभाव के वर्तमान में विकराल समस्याओं में दिखाई पड़ रहा है। पर्यावरण के विभिन्न घटकों पर पड़ने वाले प्रभावों को अल्पकालीन एवं दीर्घकालीन परिणाम को अध्ययन के प्रभावों का मूल्यांकन किया गया है। 


\section{मुरादाबाद जनपद में पर्यावरणीय निम्नीकरण और उसके प्रभाव}

\section{1. प्रस्तावना}

प्रस्तुत शोध अध्ययन क्षेत्र मुरादाबाद जनपद में पर्यावरण निम्रीकरण और उसके प्र्रभाव का अध्ययन है कि प्रत्येक मनुष्य अपने भविष्य को बेहतर बनाने का निरंतर प्रयास करता है। शायद व्यक्तिगत विकास के स्तर पर तो यह सही है, परन्तु पर्यावरण केस्तर पर मनुष्य की वर्तमान गतिविधिया, उसकी संवेदनशीलता की ओर ही इशारा करती है। हमारे आस-पास के वातावरण की वर्तमान बढ़ती समस्याऐं जैसे मृदा के वास्तविक गुणों का ह्नास, वायु असंगठन में अवांछित परिवर्तन, जल प्रदूषकों के स्तर का तेजी से वृद्धि, जैवविविधता का तेंजी से ह्नास ,ध्वनि प्रदूषण, असाध्य व स्वास्थ्य रोगों का तेजी से वृद्धि आदि पर्यावरण के साथ-साथ मानव अस्तित्व पर भविष्य संकट की तरह है। इन समस्याओं के मूल में कुछ प्राकृतिक नैतिकता एवु मूल्यों को दिन-प्रतिदिन पीछे छोड़ते जा रहे हैं। प्रकृति संसाधनों में जैसे जल संसाधन, वायु संसाधन, मृदा संसाधन, वनस्पति संसाधन, जीव-जन्तुओं आदि के मूल स्वरूप बदलते जा रहे हैं जिससे मृदा अनुर्वतता, वैश्विक तायन एवं जलवायु एवं प्रकृति आपदाओं में वृद्धि, पेय जल की समस्या आदि जैसी समस्याओं का रूप धारण कर लिया है। शोधार्थी ने अपने अध्ययन क्षेत्र जनपद मुरादाबाद के नगरीकरण का वातावरण पर पड़ने वाले प्रभावों को पर्यावरण के निम्नीकरण एवं उसके प्रभाव के वर्तमान में विकराल समस्याओं में दिखाई पड़ रहा है। पर्यावरण के विभित्र घटकों पर पड़ने वाले प्रभावों को अल्पकालीन एवं दीर्घकालीन परिणाम को अध्ययन के प्रभावों का मूल्यांकन किया गया है।

निम्नीकरण से तात्पर्य पर्यावरण के विभित्र घटकों यथा मृदा, वायु जल तथा जैवविविधता के वास्तविक गुणों एवं विशेषताओं में होने वाले अवांछनीय परिवर्तन से है। प्रकृति में सामान्य परिस्थितियों मं० निम्रीकरण एवं निर्माणकारी प्रक्रियायें एक चक्रीयरूप में घटित होती हैं एवं इनमें सन्तुलन की स्थिति बनी रहती है, परन्तु वर्तमान समय में इन तकनीकी औद्योगिक एवं वैश्वीकृत युग में मानवीय गतिविधियों के कारण प्राकृतिक संसाधनों के अतिदोहन यह चक्र असंतुलित हो रहा है। भूमि उपयोग प्रतिरूप में परिवर्तन औद्योगीकरण एवं नगरीकरण की तीव्र दर उपभोक्तावादी संस्कृति ने निम्नीकरण की दर को तीव्र कर दिया है।

मुरादाबाद जनपद में भूमि उपयोग का प्रतिरूप 2017-18 विकासखण्डवार की स्थिति (हे० में0):-

\begin{tabular}{|c|c|c|c|c|c|c|c|c|c|c|}
\hline $\begin{array}{l}\text { क्र0 } \\
\text { सं0 }\end{array}$ & विकासखण्ड & $\begin{array}{l}\text { कुल } \\
\text { प्रतिवेदित } \\
\text { क्षेत्रफल }\end{array}$ & वन & $\begin{array}{l}\text { कृष्य } \\
\text { बेकार } \\
\text { भूमि }\end{array}$ & $\begin{array}{l}\text { वर्तमान } \\
\text { परती भूमि }\end{array}$ & $\begin{array}{l}\text { अन्य } \\
\text { परती } \\
\text { भूमि }\end{array}$ & $\begin{array}{l}\text { ऊसर एवं } \\
\text { कृषि अयोग्य } \\
\text { भूमि }\end{array}$ & $\begin{array}{l}\text { कृषि अतिरिक्त } \\
\text { अन्य भूमि }\end{array}$ & चारागाह & $\begin{array}{l}\text { उद्यान, वृक्ष, } \\
\text { झाड़ियां }\end{array}$ \\
\hline 1 & ठाकुरद्वारा & 25692 & 3 & 50 & 234 & 213 & 49 & 3908 & 4 & 245 \\
\hline 2 & डिलारी & 30170 & 6 & 45 & 237 & 381 & 514 & 3954 & 4 & 112 \\
\hline 3 & छजलैट & 30019 & 20 & 117 & 507 & 213 & 87 & 3646 & 15 & 81 \\
\hline 4 & $\begin{array}{l}\text { भगतपुर } \\
\text { टांडा }\end{array}$ & 22612 & 0 & 118 & 1163 & 373 & 249 & 2917 & 8 & 155 \\
\hline 5 & मुरादाबाद & 23105 & 0 & 117 & 707 & 1165 & 218 & 3184 & 2 & 83 \\
\hline 6 & मूंठापाण्डे & 30528 & 35 & 101 & 4003 & 1059 & 445 & 3661 & 2 & 263 \\
\hline 7 & डीगरपुर & 27932 & 0 & 79 & 399 & 387 & 195 & 4955 & 24 & 108 \\
\hline \multirow[t]{4}{*}{8} & बिलारी & 25254 & 0 & 68 & 46 & 291 & 221 & 3374 & 27 & 100 \\
\hline & योग ग्रामीण & 215312 & 64 & 695 & 7296 & 4082 & 1978 & 29599 & 86 & 1153 \\
\hline & योग नगरीय & 8608 & 0 & 98 & 507 & 1343 & 143 & 3685 & 5 & 90 \\
\hline & योग जनपद & 223920 & 64 & 793 & 7803 & 5425 & 2121 & 183284 & 91 & 1243 \\
\hline
\end{tabular}

स्रोतः- 2015-16 भूमि उपयोग के आँकड़ो की पुनरावृत्ति की गयी है।

1) भूलेख अधिकारी मुरादाबाद

2) जनसांख्यिकीय पत्रिका 2017-18 मुरादाबाद

अध्ययन क्षेत्र जनपद मुरादाबाद में भूमि उपयोग प्रतिरूप का अध्ययन 2017-18 की भूलेख पत्रिका के आधार पर वर्गीकृत किया है। भूमि उपयोग का बदलता हुआ स्वरूप एव पर्यावरणीय तत्वों की कमी ही निम्नीकरण में वृद्धि किया गया है। शोधार्थी द्वारा भूमि उपयोग का प्रतिरूप विभित्र प्रखण्डों में उच्च स्तर के प्रखण्ड क्षेत्रफल के मूठापाण्डे 30528 हे०, डिलारी 30170 हे०, छजलैट 30019 हे०, डींगरपुर 27932 हे०, भूमि उच्च क्षेत्रफल है तथा भगतपुर टाड़ा 22612 हे०, मुरादाबाद 23105 हे०, बिलारी 25254 हे०, ठाकुरद्वारा 25692 हे०, निम्न क्षेत्रफल हे० विकासखण्ड है । इस प्रकार वनों का क्षेत्रफल उच्च स्तर के प्रखण्ड मूठापाण्डे 35 हे०, छजलैट 20 हे०, के प्रखण्ड है तथा बिलारी 0 हे०, डीगरपुर 0 हे०, मुरादाबाद 0 हे०, ठाकुरद्वारा 3 हे०, डिलारी 6 हे०, के प्रखण्ड निम्न स्तर पर है। कृषि बेकार भूमि का उच्च स्तर के प्रखण्ड भगतपुर टांडा 118 हे०, छजलैट 1171 हे०, मुरादाबाद 117 हे 0 , मूठापाण्डे 101 हे0, है तथा निम्न स्तर के प्रखण्ड डिलारी 45 हे0, ठाकुरद्वारा 50 हे 0 , बिलारी 68 हे 0 , डीगरपुर 79 हे 0 के प्रखण्ड है। वर्तमान परती भूमि का उच्च स्तर के प्रखण्ड मूठापाण्डे 4003 हे 0 , भगतपुर टांडा 1163 हे0, छजलैट 507 हे0, मुरादाबाद 707 हे 0 , के प्रखण्ड है तथा निम्न स्तर के प्रखण्ड बिलारी 46 हे0, ठाकुरद्वारा 234 हे0, डिलारी 237 हे 0 , डीगरपुर 399 हे० निम्न स्तर के प्रखण्ड है। अन्य परती भूमि के उच्च स्तर पर प्रखण्ड मुरादाबाद 1165 हे 0 , मूठापाण्डे 1059 हे उच्च स्तर के विकासखण्ड है तथा ठाकुरद्वारा 213 हे०, छजलैट 213 हे०, बिलारी 291 हे 0 , निम्न स्तर के प्रखण्ड है । उसर एवं कृषि अयोग्य भूमि उच्च स्तर के प्रखण्डों में डिलारी 514 हे0, मूठापाण्डे 445 हें0, भगतपुर टांडा 249 हे० के 
प्रखण्ड है तथा ठाकुरद्वारा 49 हे 0 ,छजलैट 87 हे०,निम्न स्तर के प्रखण्ड ऊसर एवं कृषि योग्य भूमि के है। कृषि के अतिरिक्त अन्य भूमि का उच्च स्तर के विकासखण्ड डींगरपुर 4955 हे०, डिलारी 3954 हे०, मूठापाण्डे 3661 हे प्रखण्ड है तथा भगतपुर टांडा 2917 हे०, मुरादाबाद 3184 हे०, बिलारी 3374 हे० निम्न स्तर के प्रखण्ड है। इस प्रकार चारागाह भूमि का विभित्र प्रखण्डों में उच्च स्तर के प्रखण्ड बिलारी 27 हे०, डींगरपुर 24 हे०, छजलैट 45 हे०, चारागाह उच्च स्तर के प्रखण्ड है तथा मुरादाबाद 2 हे०, मूठापाण्डे 2 हे०, ठाकुरद्वारा 4 हे०, डिलारी 4 हे०, भगतपुर 8 हे०, निम्न स्तर के चारागाह के प्रखण्ड है। उद्यान एवं झाड़ियां के प्रखण्डों में उच्च स्तर पर ठाकुरद्वारा 245 हे०, मूठापाण्डे 263 हे०, भगतपुर टांडा 155 हे०, डिलारी 112 हे, डींगरपुर 108 हे०, के प्रखण्ड है तथा छजलैट 81 हे०, मुरादाबाद 83 हे०, निम्न स्तर पर उद्यान एवं झाड़ियों के प्रखण्ड है। इस प्रकार शोधार्थी द्वारा पर्यावरण निम्नीकरण के अन्तर्गत भूमि उपयोग प्रतिरूप का बदलता हुआ स्वरूप का अति दोहन के द्वारा पर्यावरणीय तत्वों की गुणवत्ता दिन-प्रतिदिन कम होती जा रही है और अनेक प्रकार के पर्यावरणीय समस्या दिन-प्रतिदिन बढ़ती जा रही है। प्राकृतिक के भौतिक तत्वों में जल, वायु, मृदा, जैव विविधता के गुणों में कमी या वृद्धि के कारण ही पर्यावरण निम्नीकरण की समस्या तीव्र गति से बढ़ती जा रही है।

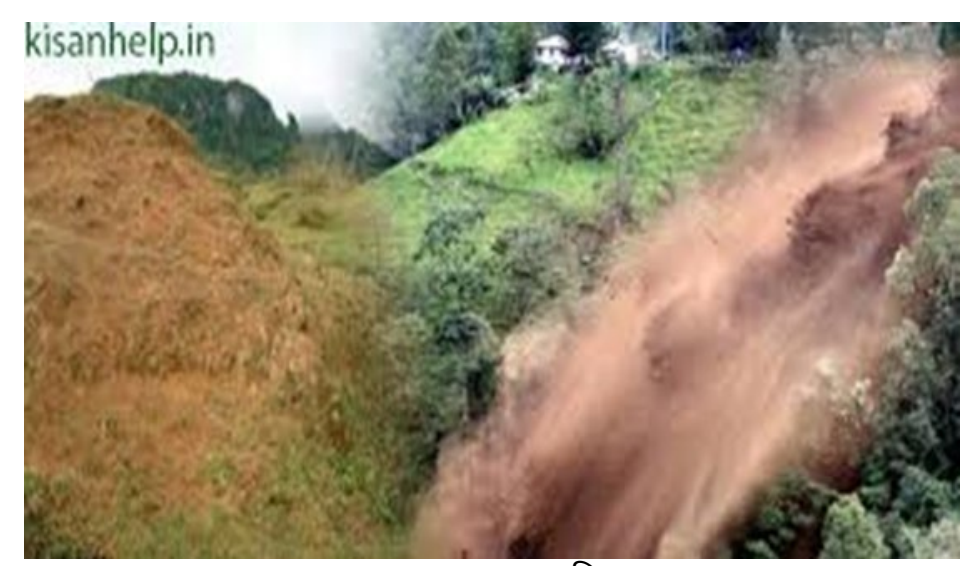

मृदा अपरदन का मानचित्र

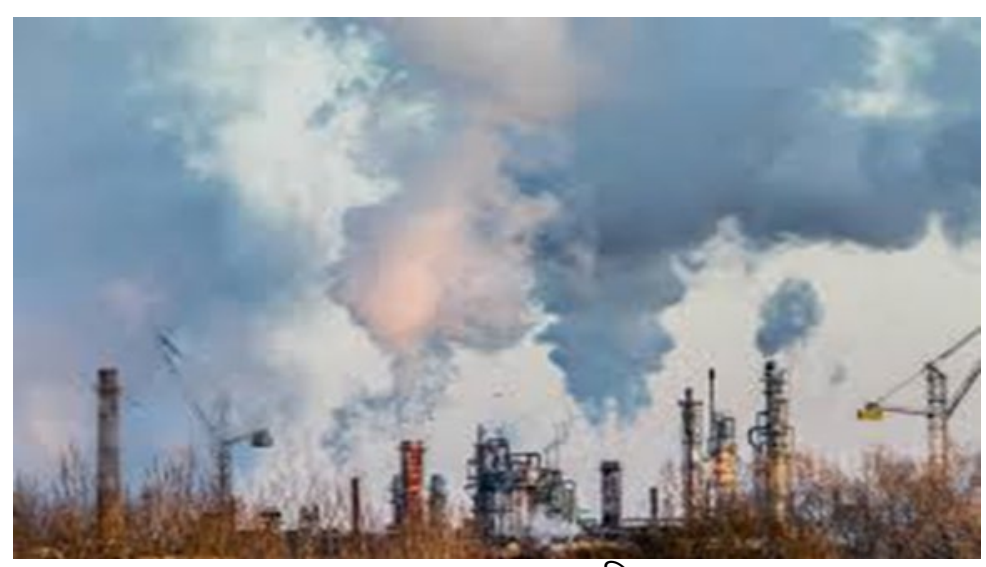

वायु प्रदूषण का मानचित्र

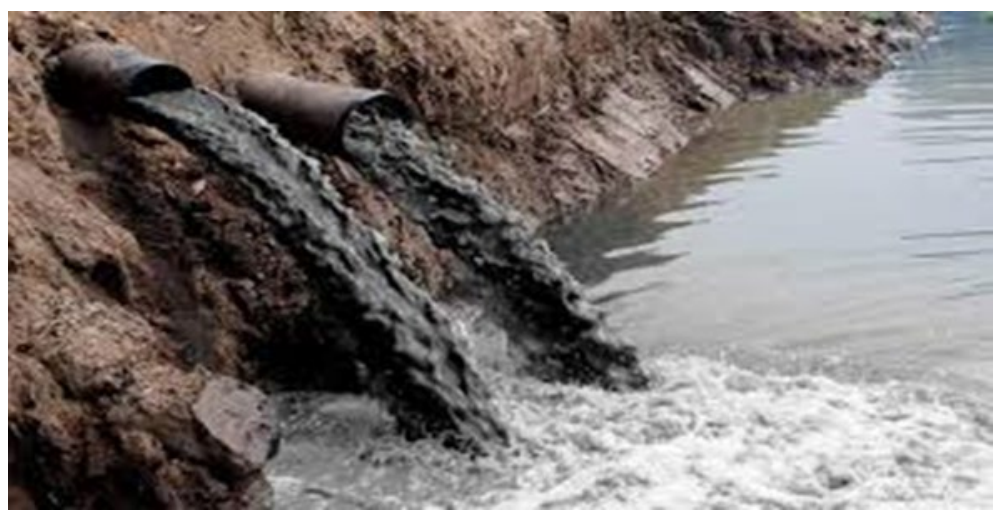

जल प्रदूषण का मानचित्र 


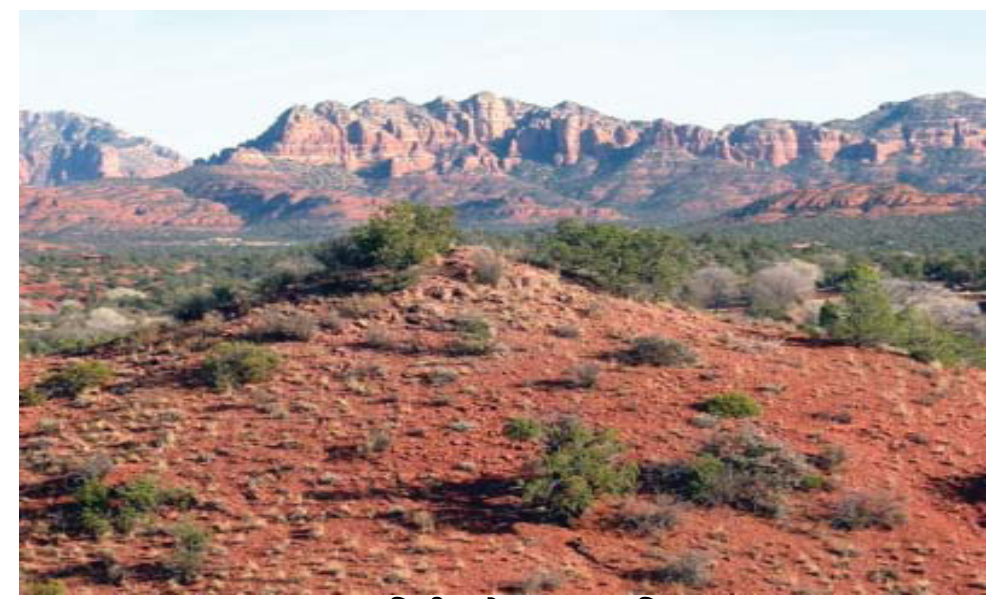

वनस्पतिहीन क्षेत्र का मानचित्र

\section{1. मुरादाबाद जनपद में पर्यावरण निम्नीकरण की स्थिति अध्ययन क्षेत्र में पर्यावरण निम्नीकरण के प्रभावों का मूल्यांकन}

भूमि उपयोग प्रतिरूप में परिवर्तन ,औद्योगिकीकरण एवं नगरीकरण की तीव्र दर, उपभोक्तावादी संस्कृति ने निम्नीकरण की दर को तीव्र कर दिया है जिसका परिणाम पर्यावरण असंतुलन के रूप में सामने आ रहा है। विशेषकर 20 वीं शताब्दी के मध्य के बाद से पर्यावरणीय समस्याओं ने वैश्विक स्वरूप धारण कर लिया है। यही कारण है कि 1987 में पर्यावरण और विकास पर ठतनदकज संदक कमीशन द्वारा सतत विकास की संकल्पना प्रस्तुत करते हुए विकास की ऐसी प्रक्रिया पर जोर दिया जो वर्तमान की आवश्यकताओं से समझौता किये बिना भविष्य की जरूरतों की पूर्ति भी कर सके।

मृदा प्राकृतिक पारितंत्र का एक महत्वपूर्ण घटक है साथ ही एक महत्वपूर्ण प्राकृतिक संसाधन भी है। वनस्पति एवं कृषि का विकास मृदा की गुणवत्ता पर ही निर्भर करता है। परन्तु वर्तमान समय में मृदा निम्रीकरण एक महत्वपूर्ण समस्या बनकर उभरी है। जिसका प्रमुख कारण मृदा अपरदन की दर में वृद्धि, मृदा संसाधन का अतिदोहन, मृदा प्रदूषण तथा मृदा लवणीकरण में वृद्धि है। मृदा के गुणों में ह्नास भविष्य में खाद्यात्र संकट के साथसाथ सामाजिक, आर्थिक एवं पर्यावरणीय समस्यायें भी उत्पत्र कर सकता है। मानव द्वारा अपनी आवश्यकताओं की पूर्ति, जैसे जनसंख्या वृद्धि के कारण आवास एवं आर्थिक विकास हेतु वन भूमियों का अतिक्रमण हो रहा है जिसके लिए बड़े पैमाने पर वृक्षों का कटाव किया जा रहा है। चूँकि वनस्पतियों मृदा को स्थायित्व प्रदान कर मृदा अपरदन की दर को नियंत्रित करती है पर वनोन्मुख के कारण वायु एवं जल जैसे अपरदन के कारकों द्वारा मृदा अपरदन अर्थात् मृदा की ऊपरी परत के कटाव की दर में वृद्धि हो रही है। जिस कारण मृदा के अनुपजाऊ होने से बंजर भूमि के क्षेत्रफल में विस्तार हो रहा है और वृहद् पैमाने पर मरूस्थलीकरण के दीर्घकालिक प्रभाव से मृदा की शुष्कता एवं लवणता में वृद्धि से मृदा की उत्पादकता का ह्नास होता है। साथ ही जल अभाव के कारण जलीय सूखा की स्थिति भी उत्पन्न होती है जो जैवविविधता के विकास हेतु प्रतिकूल परिस्थितिया ०ं उत्पन्न करती है।

वर्तमान समय में शुष्क भूमियों का तीव्र विस्तार एवं निम्नीकरण होंरहा है। शुष्क भूमियाँ पृथ्वी के स्थलीय भाग के लगभग 40-42: क्षेत्र में विस्तृत है तथा ऐसा अनुमानित है कि शुष्क भूमियों का लगभग 10-12 प्रतिशत भाग निम्नीकृत हो चुका है। लगभग 6 से 12 मिलियन वर्ग किलोमीटर क्षेत्र मरूस्थलीकरण से प्रभावित है। अफ्रीका के सहारा मरूस्थल का तीव्र गति से विस्तार अर्धशुष्क साहेल क्षेत्र में हो रहा है। रिसर्च इन्स्टीट्यूट आफ डेवलपमेन्ट के एक अध्ययन के अनुसार 1900 ई0 के बाद से सहारा मरूस्थल का लगभग 250 कि०मी० दक्षिण की ओर विस्तार हो चुका है तथा साहेल क्षेत्र के लगभग 6000 वर्ग कि0मी० क्षेत्रों में वृद्धि के कारण प्रवसन की समस्या भी उत्पन्न हुई है। यूनाइटेड नेशन कन्वेंशन के अनुसार लगभग 6 मिलियन साहेल निवासियों के उत्तरी अमेरिका और यूरोप में 1997 से 2020 के मध्य प्रवास के अनुमान है। इसी प्रकार की समस्यायें गोबी मरूस्थल के बाह्य विस्तार से देखी जा सकती है। हाल ही में 'सेन्टर फार साइन्स एण्ड एन्वायरमेन्ट' और 'डाउन टू अर्थ ' में गंजीन द्वारा जारी 'स्टेट आफ इण्डियाज एन्वायनमेन्ट 20174'के अनुसार भारत की कुल भूमि का लगभग 30 प्रतिशत भाग मरूस्थलीकरण से प्रभावित है। भातर के 29 राज्यों में से 26 राज्य मरूस्थलीकरण से प्रभावित है। रिपोर्ट ने भारत में मरूस्थलीकरण के लिए उत्तरदायी कारकों में जलीय अपरदन, वन अपरोपण, वायु अपरदन, मृदा लवणता में वृद्धि , मानव निर्मित आवासीय प्रतिरूपों को प्रमुख माना है।

मरूस्थलीकरण के अलावा जलीय अपरदन में वृद्धि के कारण जलीय स्रोतों में अवसादों के जमाव से बाढ़ की सम्भावना भी बढ़ी है। साथ-साथ मृदा की कठोर परतों के ऊपरी सतह पर आने के कारण अन्तः स्पंदन की दर में कमी से भूमिगत जलस्तर में भी कमी हो रही है। जिसके परिणाम स्वरूप पारिस्थितिक असंतुलन निरंतर बढ़ रहा है। इसके अतिरिक्त तीव्र गति से बढ़ती जनसंख्या की खाद्यात्र आवश्यकताओं की पूर्ति हेतु कृषि उत्पादकता में वृद्धि के लिए उर्वरकों के अनियंत्रित उपयोग एवं सिंचाई के साधनों जैसे नहर सिंचाई के अत्यधिक उपयोग के कारण भी मृदा की गुणवत्ता में ह्रास हो रहा है। भारत में हरित क्रान्ति के दौरान उर्वरकों के अत्यधिक उपयोग से मृदा मे पोषक तत्वों का ह्रास तथा नहर एवं नलकूप सिंचाई के कारण उत्तर पश्चिम राज्यों विशेषकर पंजाव एवं हरियाणा में मृदा लवणीकरण की समस्या में गम्भीर रूप ले लिया है। वर्तमान में नगरीकरण एवं औद्योगीकरण की तीव्र वृद्धि ने अपशिष्टों के अप्रभावशाली प्रबन्धन के कारण मृदा प्रदूषण की समस्या उत्पन्न कर दी है। वर्तमान सूचना तकनीकी 


\section{एस. के. शर्मा, ब्रह्म सिंह}

युग में इलेक्ट्रानिक सामानों के बढ़ते उपयोग ने ई-अपशिष्ट के निस्तारण की समस्या उत्पत्र कर दी है जिससे मृदा प्रदूषण ने और जटिल रूप ले लिया है जो भविष्य में पारिस्थितिकीय उत्पादकता एवं मानवीय अस्तित्व के लिए संकट उत्पन्न कर सकता है।

मृदा के साथ-साथ वायु भी पर्यावरण का महत्वपूर्ण घटक है। जैविक अस्तित्व के लिए वायु सर्वाधिक महत्वपूर्ण कारक हैं। चाहे वह वनस्पतियों में प्रकाश संश्लेषण की प्रक्रिया हो या मानव की श्वसन, उपापयची प्रक्रियाएं हों, वायु द्वारा ही इन प्रक्रियाओं के लिए गैसों की आपूर्ति होती है। परन्तु विकास की प्रक्रिया में संसाधनों के अतिदोहन से वायु की गुणवत्ता के साथ संघटन में भी प्रतिकूल प्रभाव से वायु प्रदूषण से सम्बन्धित समस्यायें वर्तमान में वैश्विक समस्यायें बनकर उभरी है। औद्योगीकरण और नगरीकरण की तीव्र विकास दर ने वायुमण्डल में ग्रीनहाउस गैसों ( कार्बन डाई आक्साइड, सल्फर डाई आक्साइड आदि ) में तीव्र वृद्धि की है। जिस कारण पृथ्वी के तापमान में अवांछित वृद्धि हो रही है। 'जलवायु परिवर्तन पर अन्तर्सरकारी पैनल की 5 वीं रिपोर्ट के अनुसार पृथ्वी के औसत तापमान में 2100 ई0 तक 1861-1880 के स्तर से $2^{\circ}$ सेन्टीग्रेड से वृद्धि की सम्भावना है। साथ ही रिपोर्ट के अनुसार वर्तमान उत्सर्जन दर के हिसाब से हमारा कार्बन बजट 30 वर्षों में समाप्त हो जायेगा। वायु निम्नीकरण से जलवायु के वैश्चिक प्रतिरूपों जैसे तापमान, वर्षा, आर्द्रता में परिवर्तन देखने को मिल रहे हैं जो क्षेत्रीय एवं वैश्विक रूप से पारिस्थितिक तन्त्र पर प्रतिकूल प्रभाव उत्पत्र कर रहा है। तापमान में वृद्धि के कारण हिमचादरों में खिसकाव एवं हिमगलन के कारण समुद्री जलस्तर में निरन्तर वृद्धि हो रही है। आई०पी०सी०सी० की रिपोर्ट के अनुसार 2100 ई0 तक कम उत्सर्जन परिद्य में समुद्री जलस्तर में 0.26-0.55 मीटर की वृद्धि होगी जबकि उच्च उत्सर्जन परिदश्य में यह वृद्धि $0.52-0.98$ मीटर की होगी। साथ ही इस रिपोर्ट में यह भी सम्भावना व्यक्त की गयी है कि पूरे विश्व में ग्लेशियर सिकुड़े हैं एवं ग्रीनलैण्ड तथा अंटार्कटिक हिमचादरों का काफी भाग पिछले 2 दशकों में खो चुका है।

इसके अतिरिक्त जलवायु परिवर्तन के कारण वर्षण प्रतिरूप में परिवर्तन से निम्न अक्षांशीय प्रदेशों में वर्षा की मात्रा, तीव्रता एवं आवृति में वृद्धि से बाढ़ की समस्या तथा मध्य अक्षांशीय क्षेत्रों में भूमध्यसागर के आस-पास के भागों में शीत ऋतु की अवधि कम होने से सूखे की समस्या उत्पत्र हो सकती है। साथ ही उच्च अक्षांशीय क्षेत्रों में हिमगलन से बाढ़, तटीय एवं द्वितीय जलमग्रता की समस्यायें उत्पत्र हो रही है। तापमान में वृद्धि से प्राकृतिक आपदाओं जैसे तटीय क्षेत्रों में चक्रवात, सूनामी, भूकम्प की तीव्रता एवं बारम्बारता बढ़ने की संभावना है।

वायु प्रदूषण के कारण समताप मंडल की ओजोन परत का क्षय तीव्र गति से हो रहा है। जिससे पृथ्वी की सतह पर पराबैगनी किरणों की तीव्रता में वृद्धि से पृथ्वी के तापमान में वृद्धि एवं वनस्पतियों की प्रकाश संश्लेषण की प्रक्रिया पर प्रतिकूल प्रभाव डाल रहा है। मानव समुदाय पर भी इसके प्रत्यक्ष प्रतिकूल प्रभाव दिखाई पड़ते हैं। आनुवांशिक संरचना में परिवर्तन एवं त्वचा कैंसर से सम्बन्धित समस्यायें मानव के लिए हानिकारक हैं। अन्तिम रूप से यह जैवविविधता के ह्नास के लिए सर्वाधिक महत्वपूर्ण कारक हैं। इसके अतिरिक्त वायु प्रदूषण से प्रदूषकों के वर्षा जल के साथ अभिक्रिया से अम्लीय वर्षण की समस्या भी उत्पत्र हो गयी है। जिससे मृदा की अम्लीयता में वृद्धि हो रही है साथ ही जल की अम्लीयता में वृद्धि से जल प्रदूषण से सम्बन्धित समस्यायें उत्पत्र हो रही है। इमारतों में भी रासायनिक अपक्षय की दर में वृद्धि होती है जो सांस्कृतिक विरासतों के लिए भी हानिकारक है। इस प्रकार वायु निम्नीकरण के कारण जहाँ बाढ़ एवं सूखा से सम्बन्धित समस्यायें उत्पन्न हो रही है वहीं जैविक समुदाय एवं पर्यावरण के अन्य घटकों पर भी प्रतिकूल प्रभाव पड़ रहा है। जिसमें दीर्घकाल में पर्यावरणीय, आर्थिक एवं सामाजिक समस्यायें उत्पत्र हो सकती है। जैसा कि वर्तमान में दिल्ली जैसे शहरों में देखा जा रहा है, जहाँ वायु प्रदूषण के उच्च स्तर के कारण पर्यावरणीय आपात की स्थिति उत्पत्र हो गयी है। आई०पी०सी०सी० की हाल ही की रिपोर्ट के अनुसार अगर वर्तमान तापन दर कायम रही तो हिमालय ग्लेशियर वर्तमान के 50 लाख वर्ग किमी० से सिकुड़कर वर्ष 2030 तक 1 लाख वर्ग किमी० रह जायेगी। जिसके प्रभाव अल्पकाल में नदियों में बाढ़ तथा दीर्घकाल में जल अभाव के कारण जलीय सूखा की स्थिति उत्पत्र होने की सम्भावना है। इसके अतिरिक्त वर्षण की मात्रा में कमी एवं मृदा नमी तनाव द्वारा मध्य भारत में साल के पेड़ों द्वारा सागवान बहुल वनों के प्रतिस्थापन का खतरा बढ़ा गया है। मानसून प्रवृत्ति में परिवर्तन से भी भारत की जैव विविधता एवं जलीय उपलब्धता पर प्रतिकूल प्रभाव पड़ रहा है।

औद्योगिक विकास के कारण औद्योगिक अपशिष्टों एवं नगरीय अपशिष्टों का अवैज्ञानिक रूप से नदियों एवं जलीय स्रोतों में निष्कासन हो रहा है जिससे पर्यावरण के महत्वपूर्ण घटक जल की गुणवत्ता में कमी हो रही है। इससे जलीय प्रदूषण में वृद्धि व जैविक समुदाय के अस्तित्व के लिए आवश्यक एवं महत्वपूर्ण के जल की उपलब्धता सीमित होती जा रही है। कृषि, औद्योगिक एवं घरेलू अपशिष्ट तथा तेल अधिप्लाव वर्तमान समय पर जलीय प्रदूषण के सर्वाधिक महत्वपूर्ण स्रोत हैं। जलीय प्रदूषण में वृद्धि के साथ स्वच्छ जल की कमी से जल तनाव की स्थिति उत्पत्र हो सकती है। प्रदूषण पदार्थों के आधिक्य के कारण जल घुली ऑक्सीजन की मात्रा घट जाती है जिससे कुछ संवेदी जीवों जैसे प्लवक, मोलस्क एवं कुछ मछलियों की मृत्यु हो जाती है। इसके अतिरिक्त पेयजल में पारा, सीसा, कैडमियम जैसी भारी धातुयें मानव स्वास्थ्य पर भी प्रतिकूल प्रभाव डालती हैं। भारत के हरित क्रान्ति के क्षेत्रों में अत्यधिक उर्वरकों के प्रयोग के कारण भूमिगत जल के प्रदूषण की समस्या देखने को मिली है। EPA- 2010 राष्ट्रीय झील आंकलन के अनुसार भारत की 20 प्रतिशत झीलों में उच्च मात्रा में नाइट्रोजन और फास्फोरक प्रदूषक पाये गये है। इससे जलीय पारितन्त्र पर प्रत्यक्ष प्रभाव पड़ता है और सुपोषण, जैव आवर्धन, प्रवाल विरंजन की प्रक्रिया तेज हो जाती है। पारामुक्त जल से प्रभावित मछलियों के सेवन से 1956 मे जापान में मिनिमता बीमारी से अनेक लोगों की मृत्यु हो गयी थी। इसके अतिरिक्त जल प्रदूषण का प्रत्यक्ष प्रभाव खाद्य उत्पादन जैसे मत्स्य उत्पादन, झींगा उत्पादन, शैवाल, कृषि आदि पर भी पड़ता है । अतः इससे आर्थिक प्रक्रियाऐं धीमी हो जाती है।

उपरोक्त विश्लेषण से यह स्पष्ट है कि पर्यावरण निम्रीकरण के तात्कालिक एवं दीर्घकालिक रूप में हानिकारक प्रभाव हो सकती है। जिस कारण बाढ़ एवं सूखा जैसी प्राकृतिक आपदाओं में वृद्धि के साथ-साथ भविष्य में खाद्यात्र संकट, मानव अस्तित्व एवं जैवविविधता के लिये भी संकट उत्पत्र हो सकता है इसलिये धारणीय विकास की संकल्पना को आधार बनाकर विकास एवं पर्यावरण में संतुलन स्थापित किये जाने की आवश्यकता है। इसके लिए पर्यावरणीय प्रबंधन को बढ़ावा देकर और पर्यावरणीय शिक्षा के माध्यम से लोगों को रूक किये जाने की आवश्यकता हे ताकि मानव समुदाय को पर्यावरण के विभित्र घटकों के मध्य अंतःक्रियाशीलता का ज्ञान हो सके। साथ ही इन घटकों पर मानवीय क्रियाकलापों के कारण पड़ने वाले नकारात्मक प्रभावों एवं उससे मानव अस्तित्व के लिये संभावित खतरों के बारे में जागरूकता फैलाई जा सके। इसके अतिरिक्त क्षेत्रीय तथा स्थानीय स्तर पर पर्यावरण के विभित्र घटकों के संरक्षण को भी बढ़ावा दिये जाने की आवश्यकता है। वैश्विक स्तर पर अन्तर्राष्ट्रीय सहयोग के माध्यम से पर्यावरण निम्नीकरण की समस्या का समाधान करने का प्रयास किया ज ना चाहिये क्योंकि पर्यावरणीय ह्नास के क्षेत्रीय कारणों का वैश्विक प्रभाव देखने को मिलता है। उदाहरणस्वरूप ब्रिटेन और जर्मनी के औद्योगीकरण का प्रभाव नार्वे और स्वीडन में अम्लीय वर्षण के रूप में दिखायी दे रहा है। 


\section{मुरादाबाद जनपद में पर्यावरणीय निम्नीकरण और उसके प्रभाव}

मृदा के संरक्षण के लिए मृदा अपरदन तथा मृदा प्रदूषण की दर को नियंत्रित किय जाने की आवश्यकता है। इसके लिये वृक्षारोपण में वृद्धि करने के साथ-साथ स्थानीय स्तर पर जैविक विधियों के अंतर्गत कृषि योग्य भूमि का प्रबंधन करने की आवश्यकता है। ढाल वाले क्षेत्रों में समोच्चरेखीय कृषि, अर्द्ध शुष्क क्षेत्रों में शेल्टर कृषि एवं मैदानी क्षेत्रों में सामान्य पट्टीदार कृषि को बढ़ावा दिया जाना चाहिये। शुष्क कृषि क्षेत्रों में प्रबंधन एवं स्थानांतरण शील कृषि पर रोक के माध्यम से भी संरक्षण किया जा सकता है।

यु निम्नीकरण के प्रबन्धन के लिये नवीकरणीय ऊर्जा स्रोतों से अनवीकरणीय ऊर्जा स्रोतों को यथासंभव प्रतिस्थापित किये जाने की आवश्यकता है। साथ ही औद्योगिक क्षेत्रों के कार्बन उत्सर्जन दर को नियन्त्रित करने के लिए उच्च तकनीकों के प्रयोग की आवश्यकता है। अपशिष्ट प्रबंधन तकनीकों को बेहतर कर और उनके उपयोग को बढ़ावा जैसे अपशिष्ट से विद्युत उत्पादन करने की आवश्यकता है जो तकनीकी हस्तांतरण के लिये अंतर्राष्ट्रीय सहयोग से पूरा हो सकता है।

महात्मा गांधी के अनुसार प्रकृति के पास मनुष्य की आवश्यकताओं के लिये सब कुछ है, परन्तु लालच के लिये नहीं। इसलिये संसाधन के अतिदोहन एवं उपभोक्तावादी संस्कृति पर नियंत्रण की आवश्यकता है विकास की अंधी दौड़ के स्थान पर विकास एवं पर्यावरण को साथ लेकर चलने से ही धारणीय विकास संभव है, अन्यथा भविष्य में मानव अस्तित्व पर ही संकट उत्पन्न हो सकता है।

\section{SOURCES OF FUNDING}

None.

\section{CONFLICT OF INTEREST}

None.

\section{ACKNOWLEDGMENT}

None.

\section{REFERENCES}

[1] जिला सांख्यिकीय पत्रिका मुरादाबाद 2017-18।

[2] तिवारी, आर० सी० , 2008, भारत का भूगोल, प्रयाग पुस्तक भवन इलाहाबाद, पृ0 602 से 623 ।

[3] भरूचा, इराक , 2006, पर्यावरण अध्ययन, ओरियंट लाॅगमैन प्राइवेट लिमिटेड, नई दिल्ली।

[4] सिंह, बी० एन0 एवं यादव, ए0 के0 2007, मानव एवं आर्थिक भूगोल।

[5] सिंह बी0 एन0, 2007, मानव भूगोल, प्रयाग पुस्तक भवन, इलाहाबाद ।

[6] सिंह, सविन्द्र, 1991, पर्यावरण भूगोल, प्रयाग पुस्तक भवन, इलाहाबाद , पृ0 272 से 307 ।

[7] कृषि भूलेख सांख्यिकी पत्रिका मुरादाबाद।

[8] दैनिक जागरण समाचार पत्र मुरादाबाद।

[9] वायु प्रदूषण नियंत्रण विभाग नई दिल्ली।

[10] इण्टरनेट पत्रिका योजना लेख आदि।

[11] जनगणना विभाग भारत सरकार 2011 ।

[12] पर्यावरण प्रदूषण नियंत्रण प्राधिकरण मुरादाबाद 2018। 